\title{
Tungsten oxide in polymer electrolyte fuel cell electrodes-A thin-film model electrode study
}

\author{
Björn Wickman $^{\mathrm{a}, *}$, Maria Wesselmark ${ }^{\mathrm{b}}$, Carina Lagergren $^{\mathrm{b}}$, Göran Lindbergh $^{\mathrm{b}}$ \\ a Competence Centre for Catalysis, Department of Applied Physics, Chalmers University of Technology, SE-412 96 Göteborg, Sweden \\ ${ }^{\mathrm{b}}$ Applied Electrochemistry, School of Chemical Science and Engineering, KTH, SE-100 44 Stockholm, Sweden
}

\section{A R T I C L E I N F O}

\section{Article history:}

Received 1 April 2011

Received in revised form 13 August 2011

Accepted 14 August 2011

Available online 23 August 2011

\section{Keywords:}

PEMFC

Fuel cell

Tungsten oxide

Platinum

Hydrogen oxidation

CO oxidation

Thermal evaporation

\begin{abstract}
A B S T R A C T
Thin films of $\mathrm{WO}_{x}$ and $\mathrm{Pt}$ on $\mathrm{WO}_{x}$ were evaporated onto the microporous layer of a gas diffusion layer (GDL) and served as model electrodes in the polymer electrolyte fuel cell (PEFC) as well as in liquid electrolyte measurements. In order to study the effects of introducing $\mathrm{WO}_{x}$ in PEFC electrodes, precise amounts of $\mathrm{WO}_{x}$ (films ranging from 0 to $40 \mathrm{~nm}$ ) with or without a top layer of $\mathrm{Pt}(3 \mathrm{~nm}$ ) were prepared. The structure of the thin-film model electrodes was characterized by scanning electron microscopy and $\mathrm{X}$ ray photoelectron spectroscopy prior to the electrochemical investigations. The electrodes were analyzed by cyclic voltammetry and the electrocatalytic activity for hydrogen oxidation reaction (HOR) and CO oxidation was examined. The impact of Nafion in the electrode structure was examined by comparing samples with and without Nafion solution sprayed onto the electrode. Fuel cell measurements showed an increased amount of hydrogen tungsten bronzes formed for increasing $\mathrm{WO}_{x}$ thicknesses and that Pt affected the intercalation/deintercalation process, but not the total amount of bronzes. The oxidation of pre-adsorbed $\mathrm{CO}$ was shifted to lower potentials for $\mathrm{WO}_{x}$ containing electrodes, suggesting that $\mathrm{Pt}-\mathrm{WO}_{x}$ is a more CO-tolerant catalyst than Pt. For the HOR, Pt on thicker films of $\mathrm{WO}_{x}$ showed an increased limiting current, most likely originating from the increased electrochemically active surface area due to proton conductivity and hydrogen permeability in the $\mathrm{WO}_{x}$ film. From measurements in liquid electrolyte it was seen that the system behaved very differently compared to the fuel cell measurements. This exemplifies the large differences between the liquid electrolyte and fuel cell systems. The thin-film model electrodes are shown to be a very useful tool to study the effects of introducing new materials in the PEFC catalysts. The fact that a variety of different measurements can be performed with the same electrode structure is a particular strength.
\end{abstract}

(c) 2011 Elsevier Ltd. All rights reserved.

\section{Introduction}

Development of new alternative electrode materials is essential in order for the polymer electrolyte fuel cell (PEFC) to be able to reach a broad market. Today, high platinum loadings are required, especially on the cathode, to obtain sufficient activity for oxygen reduction. In addition, electrode degradation causes loss of catalyst surface area and requires high initial loadings to maintain the cell performance over time. There are problems related to Pt also on the anode side where poisoning of the catalyst, by e.g. $\mathrm{CO}$, reduces the activity. Approaches to improve the electrodes and reduce their costs are continuously evaluated and include alternative catalysts or supports as well as new structures and morphologies of the catalyst layer [1]. Alternative catalysts, based on non-precious metals, Pt alloys/mixtures, and/or novel supports should preferably reduce the total amount of Pt, increase the activity, and be stable in the fuel

\footnotetext{
* Corresponding author. Tel.: +46 317725179; fax: +46 317723134

E-mail address: bjorn.wickman@chalmers.se (B. Wickman).
}

cell environment. The support material can influence the activity by spill-over effects as well as changing the electronic structure of the catalyst $[2,3]$. New support materials can improve the activity, utilization, and stability of the catalyst or of the support itself [4].

Tungsten oxide is a material which has been extensively investigated for a wide range of applications, mainly, due to its unique electrochromic properties but also for its electrocatalytic activities $[5,6]$. The electrochromism allows tungsten oxide to intercalate/deintercalate ions (of e.g. $\mathrm{H}, \mathrm{Li}, \mathrm{Na}, \mathrm{K}, \mathrm{Pb}, \mathrm{Cd}$ ) into its structure in the formation of tungsten bronzes. The most widely studied form is the hydrogen tungsten bronze where protons are inserted in the oxide structure as $\mathrm{H}_{x} \mathrm{WO}_{3}$ and $0<x<1$. The bronze formation mechanism has been the subject for numerous studies and it is suggested that the hydrogen atoms form hydroxyl bonds in the tungsten oxide, following the reaction below [7-10].

$$
\mathrm{WO}_{2}+x \mathrm{H}^{+}+x \mathrm{e}^{-} \leftrightarrow \mathrm{H}_{x} \mathrm{WO}_{2}
$$

The bronze formation is greatly affected by the water content, porosity, and also crystallinity, which in turn affect the catalytic properties of tungsten oxide [10-12]. At the same time as 
protons can be incorporated in the $\mathrm{WO}_{x}$ structure, they also have a significant mobility which means that $\mathrm{WO}_{x}$ functions as a proton conductor under these conditions [13]. The electric conductivity of mesoporous tungsten oxide has been shown to increase by 2-4 orders of magnitude, up to $10^{-3} \Omega^{-1} \mathrm{~m}^{-1}$, upon formation of hydrogen tungsten bronzes $[14,15]$. Since the hydrogen tungsten bronze formation is dependent on the water content, large variation in conductivity has been reported when varying the relative humidity [7]. Moreover, Pt supported on tungsten oxide has been shown to affect the bronze formation and both an increased intensity of the hydrogen intercalation/deintercalation peaks as well as a shift of the peak potential to higher potentials has been reported [6,16,17].

Tungsten oxide has been evaluated both as support and active catalyst in fuel cell anode as well as cathode electrodes. Sole tungsten oxide has displayed activity for hydrogen oxidation, which was attributed to high porosity and high surface area [14]. Combined Pt and tungsten oxide based catalysts have been investigated for methanol/ethanol oxidation [18-25], CO oxidation [26-30], hydrogen oxidation [14,31-34] as well as oxygen reduction [17,34-39]. Already in 1969, Hobbs and Tseung observed an enhanced activity for hydrogen oxidation on platinized tungsten oxide [31] which they further proved to be due to a hydrogen spill-over mechanism [32,33]. For methanol oxidation, the $\mathrm{Pt}$ on $\mathrm{WO}_{x}$ system has shown improved efficiency over Pt catalyst due to both the spill-over of hydrogen from $\mathrm{Pt}$ to $\mathrm{WO}_{x}$ but also the ability of $\mathrm{WO}_{x}$ to provide oxygen atoms at low potentials and thereby avoiding CO-poisoning [6,21]. Others have attributed the improved performance to an increased electrochemical active surface area (ECSA) of Pt on $\mathrm{WO}_{x}[25,34,40,41]$. The improved CO tolerance for Pt on $\mathrm{WO}_{x}$ has been shown in several studies $[14,21,27,29,30,40]$.

The spill-over of hydrogen between $\mathrm{WO}_{x}$ and Pt has been suggested as being responsible also for the increased ORR activity $[17,38]$. Furthermore, an increased activity for reduction of hydrogen peroxide has also been observed in fuel cell measurements by adding $\mathrm{WO}_{3}$ to the carbon supported platinum catalyst layer $[17,42]$. Ota et al. suggested that the observed enhancement of ORR activity on $\mathrm{Pt}-\mathrm{WO}_{3}$ is due to a reduction of Pt oxide formation when $\mathrm{Pt}$ is deposited on $\mathrm{WO}_{x}$ [37]. Shim et al. observed that $\mathrm{Pt}-\mathrm{WO}_{3} / \mathrm{C}$ catalysts rendered higher ECSAs and an improved fuel cell performance compared to $\mathrm{Pt} / \mathrm{C}$ catalyst [34]. A possible explanation for this can be that $\mathrm{WO}_{x}$ provides both protons and electrons to the supported Pt catalyst [36,43].

Tungsten oxide is also relatively stable in acidic environment, which is a prerequisite for use in polymer electrolyte fuel cell applications $[35,44,45]$. However, some dissolution of tungsten oxides has been reported $[11,30,35,45]$.

In a previous study, we examined the impact of different metal oxides on the stability and activity of platinum in thin model cathodes in a PEFC [46]. Pt on $\mathrm{WO}_{x}$ did exhibit an improved activity for oxygen reduction and possibly also an improved stability compared to Pt alone. Interesting features such as reduced platinum oxide formation and platinum catalyzed hydrogen tungsten bronze formation were also seen when Pt was deposited on $\mathrm{WO}_{x}$.

In this study, we perform a more thorough investigation of the characteristics of Pt and $\mathrm{WO}_{x}$ in the PEFC. Thin film model electrodes, fabricated by thermal evaporation of the catalyst directly onto the gas diffusion layer (GDL) are used as electrodes. This enables a direct comparison of tungsten oxide electrodes, with and without platinum. It is also possible to use the same electrodes for electrochemical evaluation in both liquid electrolyte and fuel cell. This is important since the proposed beneficial effects of tungsten oxide depend on the formation of hydrogen tungsten bronzes in which the degree of hydration plays an important role. The system is evaluated by examining HOR, CO oxidation, as well as cyclic voltammetry in inert environment. A detailed analysis of the hydrogen tungsten bronze formation is carried out and the role of Pt in this process is discussed. In particular, we show that different results may be obtained when the system is evaluated in liquid electrolyte compared to in fuel cell setup. Also, the system changes dramatically when Nafion is incorporated in the porous electrodes.

\section{Experimental}

\subsection{Model electrode preparation}

CARBEL CL gas diffusion layers were purchased from Gore Technologies and the surface was cleaned with flowing nitrogen gas prior to film deposition. Thin catalyst films were deposited by thermal evaporation in vacuum (AVAC HVC600, at about $10^{-6}$ mbar). $\mathrm{W}$ and Pt were evaporated on to the GDL at controlled thicknesses, measured with a quartz crystal microbalance sensor located in the chamber. The samples are named according to the amount of material in the following way; $y \mathrm{PtzWO}_{x}$, represents a sample with $\mathrm{y} \mathrm{nm}$ of Pt deposited on top of $z \mathrm{~nm}$ of W, which in turn was deposited on GDL. The thickness $(z)$ refers to metallic $W$, as it was deposited from a metallic W source. Subsequent analysis showed that the $\mathrm{W}$ had oxidized after the samples had been exposed to air and the samples were thus named $\mathrm{WO}_{x}$.

\subsection{Electrode morphology and chemistry characterization}

The thin film catalysts morphology was characterized by scanning electron microscopy (SEM, Leo Ultra 55 FEG) operating at $10 \mathrm{kV}$ in the secondary electron mode. Chemical characterization was performed using X-ray photoelectron spectroscopy (XPS, Perkin Elmer PHI 5000C ESCA system) using monochromatic Al K $\alpha$ radiation and $45^{\circ}$ take-off angle.

\subsection{Electrochemical evaluation}

Circular disks with a diameter of $14 \mathrm{~mm}$ were punched out from the thin film electrodes and used as working electrodes (WE) in electrochemical evaluation in liquid electrolyte and fuel cell measurements. For some of the experiments the electrodes were sprayed with a $2 \%$ Nafion in isopropanol solution. This was done approximately ten times with drying in between until the surface became shiny of a thin layer of Nafion.

A three-electrode glass cell with a platinum basket as counter electrode (CE) and the thin model electrode disk as WE was used for the liquid electrolyte experiments. A thin gold thread was attached to the carbon cloth of the thin model electrode to be used as current collector. The reference electrode was a $\mathrm{Hg} / \mathrm{Hg}_{2} \mathrm{SO}_{4}$ electrode (R601 from Radiometer) with saturated $\mathrm{K}_{2} \mathrm{SO}_{4}$ at room temperature, connected to a Luggin capillary. The reference electrode potential was 0.65 vs. the normal hydrogen electrode (NHE) at $25^{\circ} \mathrm{C}$. All potentials from liquid electrolyte measurements were shifted in respect to this and are reported with respect to the NHE. $0.5 \mathrm{M} \mathrm{H}_{2} \mathrm{SO}_{4}$ was used as electrolyte and was prepared from concentrated $\mathrm{H}_{2} \mathrm{SO}_{4}$ (pro analysi, Merck) and Milli-Q water (Millipore). All tests were done with nitrogen bubbling through the electrolyte to avoid any reactions with dissolved oxygen. Cyclic voltammetry was performed with a PAR 273A potentiostat, EG \& G Princeton, with a lower sweep limit of 0 and an upper limit of $1.35 \mathrm{~V}$ vs. NHE at $200 \mathrm{mV} \mathrm{s}^{-1}$.

In order to prepare MEAs for fuel cell testing, the thin model electrode disks were placed onto $45 \mathrm{~mm} \times 45 \mathrm{~mm}$ pieces of Nafion ${ }^{\mathrm{TM}}$ 115 membranes (Nafion 115, Aldrich). The membranes had previously been cleaned by boiling in $3 \% \mathrm{H}_{2} \mathrm{O}_{2}$ for $1 \mathrm{~h}$, in $0.1 \mathrm{M} \mathrm{H}_{2} \mathrm{SO}_{4}$ for $1 \mathrm{~h}$ and finally in three successive baths of Milli-Q water for $1 \mathrm{~h}$ each after which the membranes were dried in an oven at 

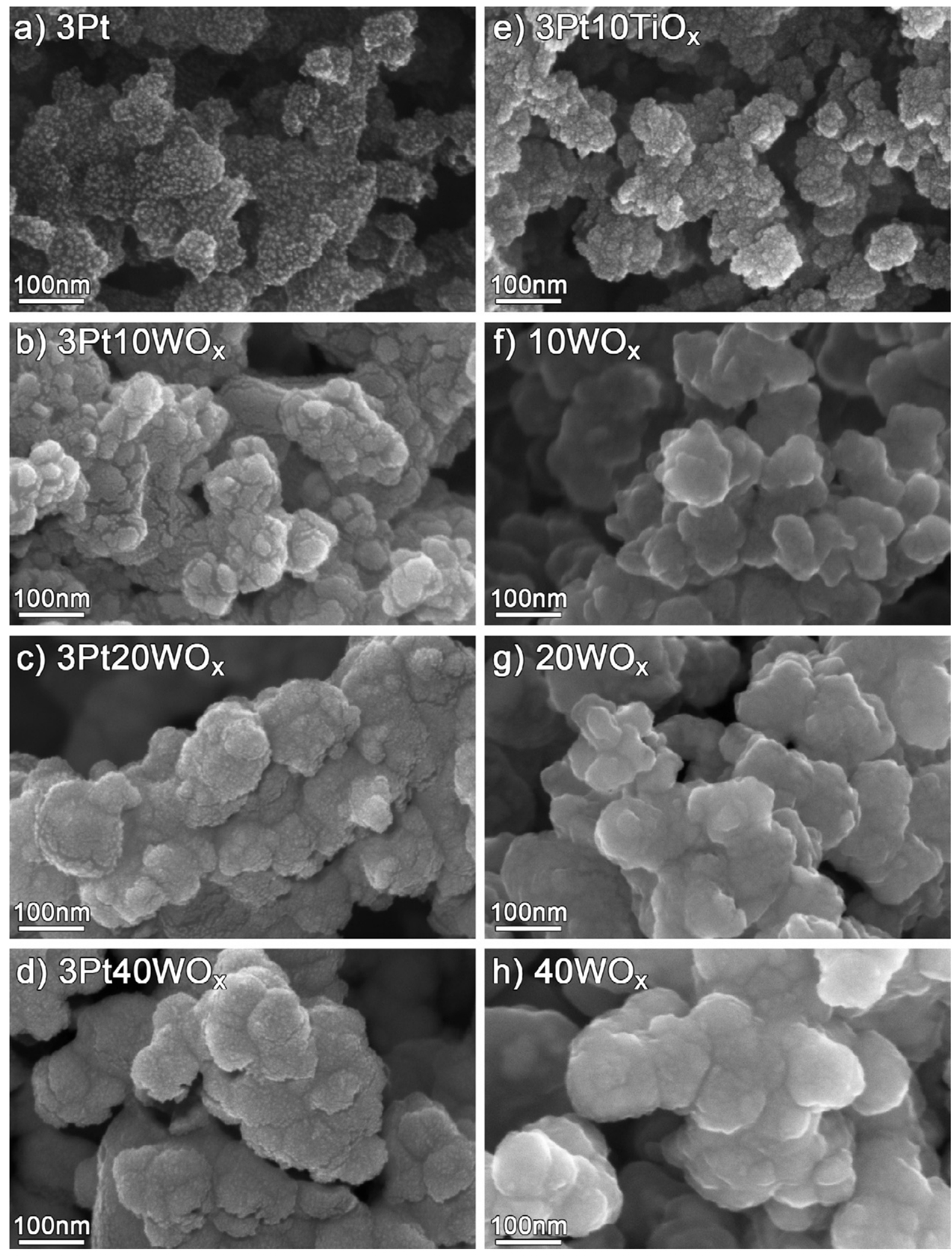

Fig. 1. SEM images of the as-prepared thin film model electrodes deposited on GDL.

$80^{\circ} \mathrm{C}$ overnight. Commercial porous ELAT electrodes (30\% Pt on Vulcan XC-72) with a loading of $0.5 \mathrm{mg} \mathrm{Pt} \mathrm{cm}{ }^{-2}$ were placed on the counter side of the membrane and used as combined counter and reference electrode (CE/RE). The MEAs (thin film electrode on $\mathrm{GDL}+$ membrane + ELAT electrode) were hot pressed at $135^{\circ} \mathrm{C}$ for $30 \mathrm{~s}$ at $1 \mathrm{MPa}$. The MEA was mounted in a laboratory PEEK (polyether-etherketone) fuel cell, described elsewhere [47], with cylindrical, $30 \mathrm{~mm}$ in diameter, graphite current collector with spirally formed gas channels and a clamping force over the current collectors of $380 \mathrm{~N}$. 
For the standard case, if nothing else is mentioned, the gases were humidified in heated humidifiers (Fuel Cell Technologies Inc.) held at $77^{\circ} \mathrm{C}$, resulting in $90 \%$ relative humidity (RH) in the fuel cell with a cell temperature of $80^{\circ} \mathrm{C}$. Cyclic sweeps were performed with $\mathrm{O}_{2}$ or $\mathrm{N}_{2}$ on the WE and $5 \% \mathrm{H}_{2}$ in Ar at the CE/RE fed in excess at $1 \mathrm{ml} \mathrm{s}^{-1}$. The very low loading on the $\mathrm{WE}$ ( $3 \mathrm{~nm}$ of Pt corresponds to a Pt loading of about $6 \mu \mathrm{g} \mathrm{cm}^{-2}$ ), compared to the porous $\mathrm{CE} / \mathrm{RE}$, made it possible to use $5 \% \mathrm{H}_{2}$ in $\mathrm{Ar}$ which diminishes crossover of hydrogen to the WE. The CE/RE was also assumed not to be polarized due to the low current density. All measured potentials from the fuel cell tests are referred to the reversible hydrogen electrode (RHE) and the potential have therefore been corrected for the $45.5 \mathrm{mV}$ shift due to the lower hydrogen partial pressure $\left(5 \% \mathrm{H}_{2}\right.$ in Ar).

After $2 \mathrm{~h}$ of constant gas flows at the correct temperature, the electrochemical measurements always started with cyclic sweeps in nitrogen to get a description of the surface processes on the electrode. This was followed by an activation procedure by 2000 cycles at $20 \mathrm{mV} \mathrm{s}^{-1}$ between 0.6 and $0.9 \mathrm{~V}$ vs. RHE in oxygen after which further measurements were performed.

CO-stripping curves were recorded in the potential window between 0.05 and $1.2 \mathrm{~V}$, at a sweep rate of $20 \mathrm{mV} \mathrm{s}^{-1}$. After a cycle in humidified $\mathrm{N}_{2}$ gas, the potential scan was stopped at $0.15 \mathrm{~V}$ and the gas flow shifted to CO-containing gas ( $2 \%$ CO balanced with $\mathrm{Ar}$ ) for $\mathrm{CO}$ adsorption during $2 \mathrm{~min}$. Thereafter the inlet gas was shifted back to nitrogen for $5 \mathrm{~min}$, to flush out remaining $\mathrm{CO}$ in the cell, before subsequent stripping.

Polarization curves for $\mathrm{H}_{2}$ oxidation were performed with $100 \%$ $\mathrm{H}_{2}$ fed in excess at $2.75 \mathrm{ml} \mathrm{s}^{-1}$ on both the WE and CE/RE. The potential was swept between -0.1 and $0.5 \mathrm{~V}$, at $10 \mathrm{mV} \mathrm{s}^{-1}$ and between -0 and $0.5 \mathrm{~V}$ at $1 \mathrm{mV} \mathrm{s}^{-1}$. To determine the cell resistance, ac impedance spectra was conducted with an Autolab PGSTAT302N from $100 \mathrm{kHz}$ to $1 \mathrm{~Hz}$, both in $\mathrm{N}_{2}$ and $\mathrm{H}_{2}$, at several potentials. Nova 1.5 was used for analyzing the data and the real axis intercept was used as a measure of the cell resistance.

\section{Results and discussion}

\subsection{Materials characterization}

The structure of the thin model electrodes was characterized by SEM and XPS prior to the electrochemical evaluation. Fig. 1 shows SEM micrographs of all samples, as-prepared. As can be seen, evaporation of $3 \mathrm{~nm}$ Pt on GDL results in a non-continuous Pt film of separated nanoparticles, roughly $3-6 \mathrm{~nm}$ in size. This result agrees well with previously presented data for physical deposition of $\mathrm{Pt}$ on porous carbon supports $[46,48]$. The separated nanoparticles are the result of the fact that Pt growth proceeds via the formation of isolated nanoparticles due to Pt atom surface diffusion on the carbon support [48]. It can also be noted that the structure of this electrode is very similar to a conventional PEFC electrode and is thus a relevant model system. However, in this case the Pt particles are situated only in a very thin domain of the electrode as the Pt deposits only on the exposed parts (projected area) of the support. In Fig. 1 it can also be seen that tungsten forms a different structure compared to Pt. Deposition of $10 \mathrm{~nm}$ of $\mathrm{W}$ results in a smooth film that fully covers the exposed carbon. This is the result of both the facts that the amount of $\mathrm{W}$ was larger than the amount of Pt, and the intrinsic interactions between $\mathrm{W}$ and carbon. W efficiently wets the carbon and does not form isolated particles, even at lower thicknesses [46]. Due to the lower contrast between Pt and W compared to Pt and carbon in the SEM, it is somewhat difficult to identify the Pt structure precisely. However, it is clearly seen that electrodes with $\mathrm{Pt}$ on $\mathrm{W}$ have a rougher surface than those with only W. Pt seems to form more or less isolated particles also on W,

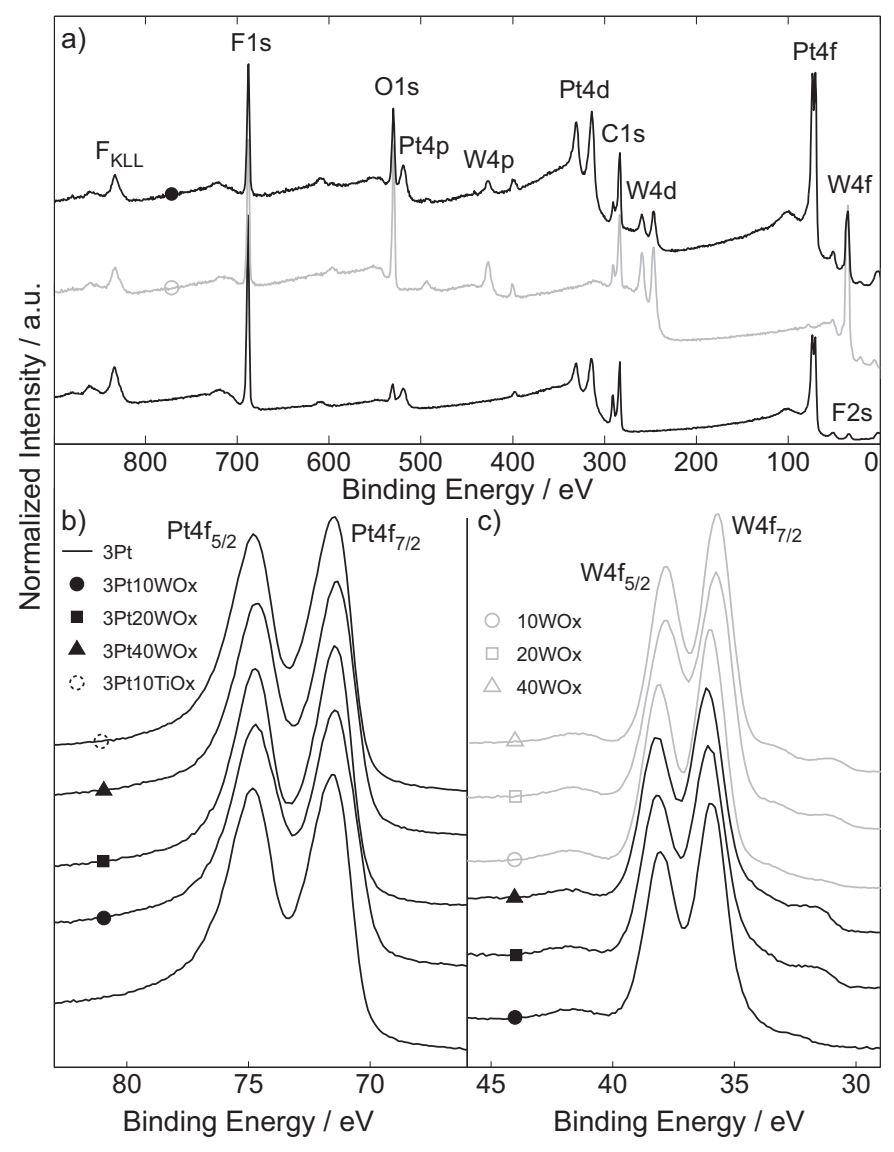

Fig. 2. XPS spectra presented as overview spectra (a) and high resolution scans of $\mathrm{Pt}(4 \mathrm{f})(\mathrm{b})$ and $\mathrm{W}(4 \mathrm{f})$ (c) regions for all as-prepared electrodes of thin films deposited on GDL.

perhaps with slightly smaller particle sizes than those on carbon. An increased Pt dispersion has been discussed as one of the beneficial effects of supporting Pt on tungsten oxides [34,39]. From this analysis, however, we see no or minor differences in the Pt structure on tungsten oxide compared to carbon. Another explanation for the increased ECSA of Pt might be that the proton conducting properties of the $\mathrm{WO}_{x}$ provides proton contact to more of the Pt in the electrode. For the $3 \mathrm{Pt} 10 \mathrm{TiO}{ }_{x}$ sample, used as reference for some of the measurements in this work, the Pt forms isolated nanoparticles while Ti effectively wets the carbon. Although there are some structural differences between the $\mathrm{TiO}_{x}$ and $\mathrm{WO}_{x}$ samples, the structure of the Pt is essentially similar.

Both $\mathrm{W}$ and Ti were evaporated from the elements in metallic form, but due to both the low amount of oxygen present in the chamber during evaporation and the exposure to atmosphere after deposition, the thin metal films are expected to spontaneously oxidize. XPS analysis was employed to characterize the chemical state of all electrodes prior to the electrochemical measurements. Fig. 2 shows overview spectra from 0 to $900 \mathrm{eV}$ for the $3 \mathrm{Pt}, 10 \mathrm{WO}_{x}$, and $3 \mathrm{Pt} 10 \mathrm{WO}_{x}$ samples (Fig. 2a) as well as high resolutions scans on the $\mathrm{Pt}(4 \mathrm{f})$ (Fig. 2b) and W(4f) (Fig. 2c) core level regions for all samples. To compensate for charging effects, arising mainly from small variations in contacting the samples during measurements, the spectra were shifted to position the main $\mathrm{C}(1 \mathrm{~s})$ peak at a binding energy of $284.5 \mathrm{eV}$. These effects were minor, since the GDL is a good electric conductor and no spectra were shifted more than $1 \mathrm{eV}$. The peak position of the $\operatorname{Pt}\left(4 \mathrm{f}_{7 / 2}\right)$ core level electrons was found to be $71.4 \pm 0.1 \mathrm{eV}$ for all Pt containing samples, indicating that the Pt was in metallic state [49] and that there was no influence on the binding energy from the support materials. For the $W\left(4 f_{7 / 2}\right)$, the 


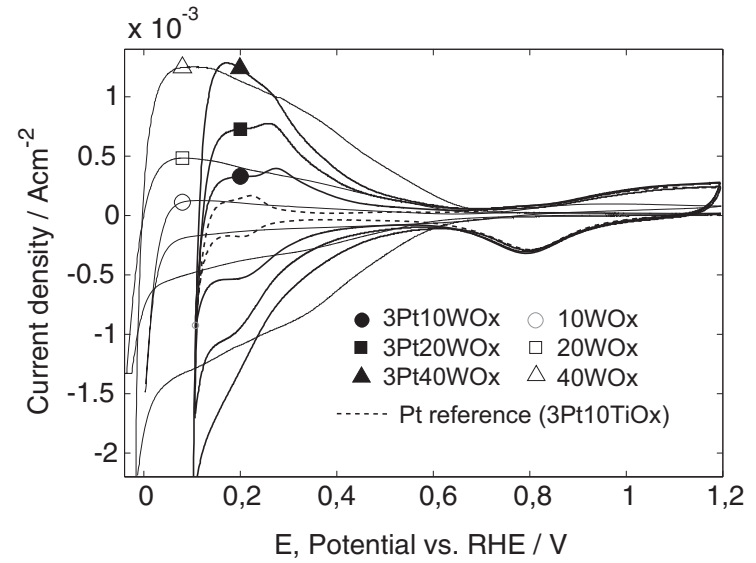

Fig. 3. Cyclic voltammetry of electrodes with varying thickness of $\mathrm{WO}_{x}$, without (grey) as well as with $3 \mathrm{~nm}$ Pt on top (black). $3 \mathrm{Pt}^{10 \mathrm{TO}_{x}}$ (dashed) is shown as reference. The voltammograms were recorded in a single cell fuel cell at $80^{\circ} \mathrm{C}$ and $90 \%$ $\mathrm{RH}$ at a scan rate of $200 \mathrm{mV} \mathrm{s}^{-1}$.

peak position was found to be $35.9 \pm 0.2 \mathrm{eV}$ for all $\mathrm{W}$ containing samples, which agrees well with $\mathrm{WO}_{3}$ [49]. However, due to the low penetration depth of the XPS, it is not certain that the entire tungsten film has formed $\mathrm{WO}_{3}$ and, moreover, it is possible that the oxidation state of the films may change during the electrochemical measurements and, therefore, the tungsten films will be referred to as $\mathrm{WO}_{x}$.

\subsection{Hydrogen tungsten bronze formation}

In order to study the formation of hydrogen bronzes and the interaction between $\mathrm{Pt}$ and $\mathrm{WO}_{x}$ in this process, samples with varying thicknesses of $\mathrm{WO}_{x}$, with and without a top layer of $3 \mathrm{~nm} \mathrm{Pt}$ were analyzed in the fuel cell. Fig. 3 shows cyclic voltammograms of electrodes with $\mathrm{WO}_{x}$ thicknesses from 10 up to $40 \mathrm{~nm}$. Most of the current response at potentials below about $0.5 \mathrm{~V}$ is resulting from the formation of hydrogen bronzes. For the Pt containing samples, however, some of the current in this region stems from hydrogen adsorption/desorption $\left(\mathrm{H}_{\mathrm{UPD}}\right.$ ) on Pt. To illustrate the current from $\mathrm{H}_{\mathrm{UPD}}$ on Pt, the $3 \mathrm{Pt} 10 \mathrm{TiO}_{x}$ sample is displayed as reference. This sample was used since it was shown in a previous study [46], which will be discussed further below, that the electrochemically active surface area (ECSA) of Pt is increased when deposited on $\mathrm{WO}_{x}$ and $\mathrm{TiO}_{x}$ compared to Pt deposited on the GDL. With $3 \mathrm{Pt} 10 \mathrm{TiO}{ }_{x}$ the ECSA was similar to $3 \mathrm{Pt} 10 \mathrm{WO}_{x}$, but the sole $\mathrm{TiO}_{x}$ do not display any activity in the $\mathrm{H}_{\mathrm{UPD}}$ region, in contrast to $\mathrm{WO}_{x}$.

For all samples with $\mathrm{Pt}$, the onset potential for bronze formation was shifted to lower potentials, which is contrary to the observations made by Kulesza et al. [16,17]. Actually, both the inclusion and exclusion of protons was shifted to lower potentials when Pt was present. The rates of the reversible bronze formation were also higher when Pt was present. This indicates that Pt is involved in the bronze formation process. However, when comparing the charges in the $\mathrm{H}_{\mathrm{UPD}}$ and bronze formation region of the electrodes with and without platinum it was found that Pt had no or minor effects on the amount of bronze formation. The charges were integrated down to the same potential and the Pt containing samples were corrected for the $\mathrm{H}_{\mathrm{UPD}}$ charge determined from the $\mathrm{WO}_{x}$-free $3 \mathrm{Pt} 10 \mathrm{TiO}{ }_{x}$. The resulting charge should correspond to the bronze formation and was similar between samples with and without Pt for the same thickness of $\mathrm{WO}_{x}$. It is possible that the bronze charge was slightly higher for the thinner $\mathrm{WO}_{x}$ films $(10$ and $20 \mathrm{~nm}$ ) and slightly lower for the thickest $\mathrm{WO}_{x}$ film $(40 \mathrm{~nm})$ when Pt was present, but the differences were hardly significant. The hydrogen evolution did start at lower potentials on the electrodes with only $\mathrm{WO}_{x}$ but the shape
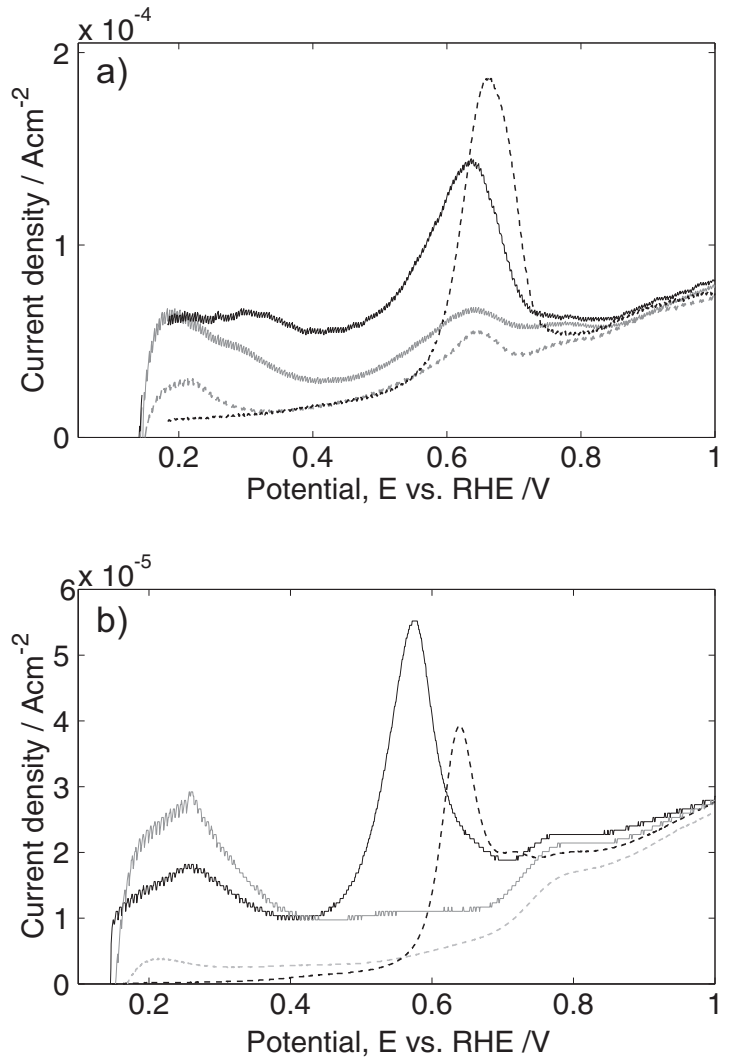

Fig. 4. CO-stripping on $3 \mathrm{Pt}$ (dashed) and $\mathrm{Pt}$ on $\mathrm{WO}_{x}$ (solid) for electrodes with Nafion coating (a) as well as without Nafion (b). Black lines represent the first positive scan whereas the grey lines are the second positive scan. For the $\mathrm{WO}_{x}$ samples, $3 \mathrm{Pt} 10 \mathrm{WO}$ was used in the measurements shown in (a) and $1.5 \mathrm{Pt} 10 \mathrm{WO}_{x}$ was used in (b). The voltammograms were recorded in a single cell fuel cell at $80^{\circ} \mathrm{C}$ and $90 \% \mathrm{RH}$ at a scan rate of $20 \mathrm{mV} \mathrm{s}^{-1}$

of the voltammogram did not change if the lower sweep limit was increased.

The apparent difference in onset potential may, to some extent, come from the overlap with $\mathrm{Pt}$ oxide reduction on the $\mathrm{PtWO}_{x}$ electrodes, but cannot fully explain large difference observed on $40 \mathrm{WO}_{x}$ with and without Pt. It should be mentioned that initially, all $\mathrm{WO}_{x}$ electrodes with $3 \mathrm{~nm}$ Pt on top show similar response in the cyclic voltammograms and not until after activation, the increasing charge in the $\mathrm{H}_{\mathrm{UPD}}$ region with increasing $\mathrm{WO}_{x}$ thickness could be seen. The sweep rate was varied between 20 and $1000 \mathrm{mV} \mathrm{s}^{-1}$, which had no impact on the charge in the bronze formation region and the reaction is therefore assumed to be a thermodynamically controlled surface process under these conditions.

\subsection{CO oxidation}

CO-stripping was performed on Pt and $\mathrm{PtWO}_{x}$ electrodes both with and without Nafion and the results are shown in Fig. 4a and b, respectively. For the Pt sample, the oxidation of CO is similar to what has previously been shown in fuel cell measurements [50], with a distinct stripping peak at $0.64 \mathrm{~V}$. On the $\mathrm{PtWO}_{x}$ samples, the oxidation starts at much lower potentials. As seen in Fig. 4a, a pre-peak between 0.2 and $0.4 \mathrm{~V}$ vs. RHE is visible before the main peak around $0.62 \mathrm{~V}$ vs. RHE appears. These results are similar to observations made by others [25,28,29], and the pre-peak has been argued to be caused by oxidation of $\mathrm{CO}$ at $\mathrm{WO}_{x}$ sites close to $\mathrm{Pt}$ sites [29]. However, in the CO-stripping on the electrodes without Nafion (Fig. 4b), it seems that the peak is related to the desorption of hydrogen from the hydrogen tungsten bronzes. In the experiments performed by Lebedeva et al. [28] and Maillard and co-workers 


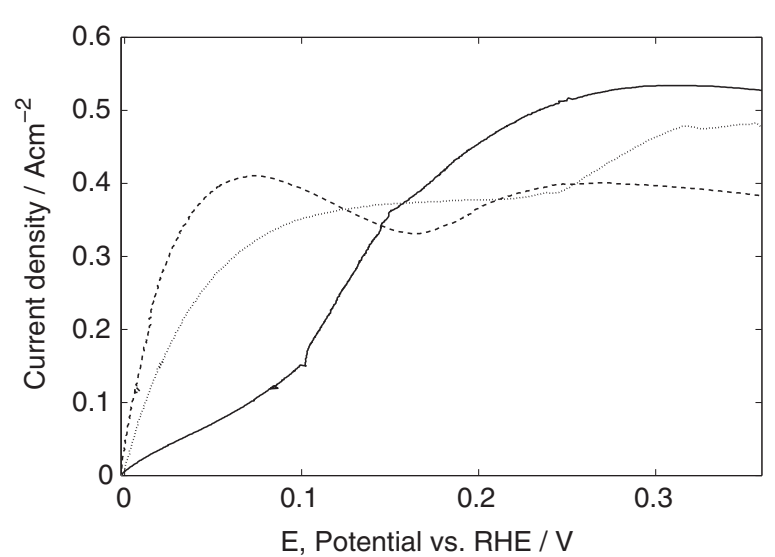

Fig. 5. Hydrogen oxidation at $1 \mathrm{mV} \mathrm{s}^{-1}$ on $3 \mathrm{Pt}$ (dashed), $3 \mathrm{Pt} 10 \mathrm{WO}_{x}$ (dotted) and $3 \mathrm{Pt} 40 \mathrm{WO}_{x}$ (solid) recorded in a single cell fuel cell at $80^{\circ} \mathrm{C}$ and $90 \% \mathrm{RH}$.

[26,29], measurements of the produced $\mathrm{CO}_{2}$ confirmed that the pre-peak, at least partly, was a result of $\mathrm{CO}$ oxidation. However for the electrodes used in this study and due to the observations in Fig. 4b, the pre-peak may also come from hydrogen desorption from the tungsten bronze which was not covered by $\mathrm{CO}$. The fact that $\mathrm{CO}$ oxidation is shifted to lower potentials for the $\mathrm{PtWO}_{x}$ samples indicates that $\mathrm{PtWO}_{x}$ is more tolerant for $\mathrm{CO}$ than Pt alone. In a recent study, Micoud et al. [26] suggested that the access to oxygen species in the form of oxy-hydroxide groups (W-OH) increases the activity for $\mathrm{CO}$ oxidation at potentials up to $0.6 \mathrm{~V}$ vs. RHE. They also suggest that the transport of $\mathrm{CO}$ to the active sites, the Pt- $\mathrm{WO}_{x}$ interface, is rate determining. We found, similar to Micoud et al., that a lower sweep rate increased the charge under the CO oxidation peak which may confirm the importance of diffusion of $\mathrm{CO}$ to the reactive sites. In Fig. $4 \mathrm{~b}$, the $\mathrm{CO}$ oxidation charge is higher for $1.5 \mathrm{Pt}$ on $10 \mathrm{WO}_{x}$ than for $3 \mathrm{Pt}$, and could possibly be explained by a higher electrochemically active surface area of the $\mathrm{PtWO}_{x}$ sample due to the proton conductivity of the $\mathrm{WO}_{x}$. In this study, we have not examined the ability of $\mathrm{PtWO}_{x}$ to catalyze the reduction of $\mathrm{CO}_{2}$ which is an important issue when using reformate feed [28]. Lebedeva et al. studied the reduction of $\mathrm{CO}_{2}$ on $\mathrm{PtWO}_{x}$ electrodes and found that $\mathrm{CO}$ builds up on Pt sites with time, but more slowly than on pure Pt [28].

\subsection{Hydrogen oxidation}

The activity for hydrogen oxidation was examined with pure $\mathrm{H}_{2}$ on both the WE and the CE/RE. Due to the high loading of the $C E$, no or minor polarization losses were assumed to occur on that electrode. In Fig. 5 the hydrogen oxidation polarization curves of $3 \mathrm{Pt}, 3 \mathrm{Pt} 10 \mathrm{WO}_{x}$ and $3 \mathrm{Pt} 40 \mathrm{WO}_{x}$ are displayed. The curves were iR-corrected by impedance spectroscopy and the values used for iR-correction were 290,120 and $450 \mathrm{~m} \Omega \mathrm{cm}^{2}$ for $3 \mathrm{Pt}$, $3 \mathrm{Pt} 10 \mathrm{WO}_{x}$ and $3 \mathrm{Pt} 40 \mathrm{WO}_{x}$, respectively. At low potentials, 3Pt displays slightly higher current densities than $3 \mathrm{Pt} 10 \mathrm{WO}_{x}$ and much higher current densities than $3 \mathrm{Pt} 40 \mathrm{WO}_{x}$. At higher potentials, the current starts to bend off and all electrodes reach a limiting current. This current is most likely limited by kinetics and not by mass transport, which was discussed in more detail in a recent study [51]. The higher limiting current densities seen for $3 \mathrm{Pt} 40 \mathrm{WO}_{x}$ and $3 \mathrm{Pt} 10 \mathrm{WO}_{x}$ are suggested to originate from their higher ECSA and could be related to the proton conductivity and hydrogen permeability of the $\mathrm{WO}_{x}$ film. The difference in initial slope between the samples may be due to uncompensated resistance from the limited electron conduction in the $\mathrm{WO}_{x}$, and should be higher for a thicker layer of $\mathrm{WO}_{x}$ The deintercalation of protons in the $\mathrm{PtWO}_{x}$ samples at low potentials could possibly also have a negative effect on the hydrogen oxida-

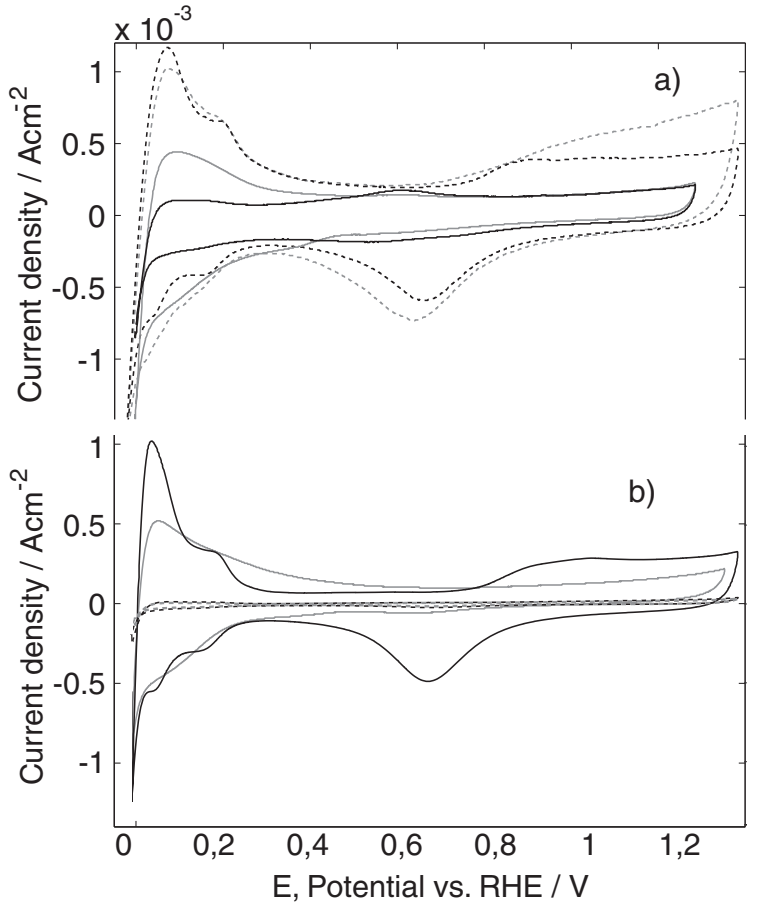

Fig. 6. Cyclic voltammograms of $3 \mathrm{Pt}$ (dashed) and $3 \mathrm{Pt} 10 \mathrm{WO}_{x}$ (solid) after 10 cycles (grey) and 150 cycles (black) for electrodes with Nafion coating (a) as well as without Nafion (b). The voltammograms were recorded in $0.5 \mathrm{M} \mathrm{H}_{2} \mathrm{SO}_{4}$ at room temperature at a scan rate of $200 \mathrm{mV} \mathrm{s}^{-1}$.

tion, resulting in the low current densities at low potentials for Pt on $\mathrm{WO}_{x}$. The impedance spectroscopy gives a response from the whole electrode surface, i.e. Nafion in contact with $\mathrm{WO}_{x}$, and not only from the active Pt sites. Since $\mathrm{WO}_{x}$ acts as both proton and electron conductor, it is unclear how the response will be for the impedance spectra. In addition, the electron and proton conductivity is changing with the inclusion/exclusion of hydrogen, which changes with potential, however no changes in the high frequency intercept were seen in the potential range from 0.02 to $0.55 \mathrm{~V}$. Even though the performances of the PtWOx electrodes are worse than Pt at the relevant anode potentials, they have a larger electrochemically active surface area for hydrogen oxidation.

\subsection{Electrochemically active surface area and stability}

After fabrication, the model electrodes do not contain any ionomer. However, Nafion can be sprayed on top of the electrode to yield a high catalyst-Nafion contact without changing the structure of the catalyst, which was also done in the CO-stripping measurements above. This enabled evaluation of the influences of Nafion while assuring that the rest of the electrode structure was constant. The amount of Nafion deposited on the catalyst, in this work, is higher than that of a typical electrode and the motivation for this was to ensure a high Pt utilization that was also similar for the different electrodes. However, this implies that the effects of Nafion observed here are somewhat exaggerated. Nonetheless, these effects should be present also for thinner layers, although less pronounced.

Fig. 6a shows cyclic voltammograms of Nafion coated 3Pt and $3 \mathrm{Pt} 10 \mathrm{WO}_{x}$ in liquid electrolyte after 10 and 150 cycles. 3Pt displayed those for platinum typical hydrogen adsorption/desorption peaks (HUPD), which became more pronounced after 150 sweeps whereas the charge in the Pt oxide region decreased slightly. The rather large double layer capacitance reveals that the wetting of the electrode and GDL was high as a consequence of the Nafion impregnation. The hydrogen adsorption charge of Pt in liquid 
electrolyte may then be used as a measure of the maximum available ECSA of the thin Pt model electrodes. For the 3Pt sample, the ECSA per geometric area was found to be $3.1 \mathrm{~cm}^{2} \mathrm{~cm}^{-2}$, which agrees well with the SEM image shown in Fig. 1a. Initially, the $3 \mathrm{Pt} 10 \mathrm{WO}_{x}$ sample exhibited a lower charge in the $\mathrm{H}_{\mathrm{UPD}}$ region than the 3Pt and without the characteristic Pt or Pt oxide features observed. After 150 sweeps, the ECSA had decreased even further, suggesting a deactivation of the Pt catalyst or Nafion layer. This could be caused by dissolution of $\mathrm{WO}_{x}$ or other structural changes making the electrode electrochemically inactive. Dissolution of the $\mathrm{WO}_{x}$ has previously been observed by Chen and Tseung [45], but the effect was reduced by covering the surface with Nafion. In our case, the decrease in ECSA was seen for several repeated measurements of different Pt on $\mathrm{WO}_{x}$ samples. Pereira et al. [30] suggested that dissolved $\mathrm{WO}_{x}$ can induce degradation of Nafion and decrease proton conduction, which might be a possible explanation for these results. Fig. 6b displays the same electrodes as in Fig. 6a, but without Nafion coating. The initial cyclic voltammogram of $3 \mathrm{Pt} 10 \mathrm{WO}_{x}$ resembles the initial cycle with Nafion coating, but with a smaller double layer capacitance charge. This is in contrast to 3Pt without Nafion, which displayed a much lower ECSA than the Nafion coated sample. The explanation may be a higher hydrophobicity of the GDL, making the wetting of the 3Pt electrode difficult, without Nafion present. Obviously, $10 \mathrm{~nm}$ of $\mathrm{WO}_{x}$ on top of the carbon was enough to improve the wettability of the $3 \mathrm{Pt} 10 \mathrm{WO}_{x}$ electrode. After 150 sweeps, platinum oxidation and reduction peaks appeared on the $3 \mathrm{Pt} 10 \mathrm{WO}_{x}$ sample and more distinct hydrogen adsorption/desorption peaks were seen. In fact, the voltammogram of $3 \mathrm{Pt} 10 \mathrm{WO}_{x}$ became similar to the voltammogram of 3Pt with Nafion. As described above, dissolving $\mathrm{WO}_{x}$ might have deactivated the catalyst or ionomer when Nafion was present, but without the Nafion coating, such dissolved $\mathrm{WO}_{x}$ should simply diffuse into the solution. However, the $\mathrm{WO}_{x}$ dissolution must in either case be very low, as it would otherwise lead to detachment of Pt. As this was not seen, it is likely that the $\mathrm{WO}_{x}$ was still present and ensured good contact between the Pt and the electrolyte. In fact, the $\mathrm{H}_{\mathrm{UPD}}$ as well as the Pt oxide reduction peaks is almost similar on the $3 \mathrm{Pt} 10 \mathrm{WO}_{x}$ sample without Nafion and the 3Pt with Nafion. This implies that, under these conditions, a film of $\mathrm{WO}_{x}$ under the Pt can replace a Nafion layer on top.

Due to the different behavior of Pt and $\mathrm{PtWO}_{x}$ electrodes with and without Nafion and the changing $\mathrm{PtWO}_{x}$ electrodes, no complete evaluation of the bronze formation was made in liquid electrolyte. However, it can be noted that no clear signs of bronze formation were observed in liquid electrolyte compared to in fuel cell, but this was not investigated further in this study.

In our previous study [46], it was shown that depositing Pt on $10 \mathrm{~nm}$, or thicker, films of $\mathrm{TiO}_{x}$ or $\mathrm{WO}_{x}$ led to an increased ECSA of Pt, compared to having Pt directly on the GDL, in fuel cell measurements. This effect was not seen for thinner films of $\mathrm{TiO}_{x}$ or $\mathrm{WO}_{x}$ $(3 \mathrm{~nm})$, which showed an almost identical Pt area as the reference Pt on GDL sample [46]. As a result of further investigations, we consider that the increase in surface area for films of $10 \mathrm{~nm}$ and more, to a large part can be explained by the proton conducting properties of both $\mathrm{TiO}_{x}$ and $\mathrm{WO}_{x}[13,43,52]$, perhaps in combination with an increased wetting of the GDL. When thinner films $(\leq 3 \mathrm{~nm})$ are deposited on the porous GDL, it is likely that they are not fully covering the carbon surface and, thus, the proton transport path is interrupted.

Fig. 7 shows the same type of CV curves as in Fig. 6, but measured in fuel cell setup. In Fig. 7a it can be seen that electrodes sprayed with Nafion prior to hot pressing attain a significantly higher ECSA and also that the amount of Pt oxide formation on the $3 \mathrm{Pt} 10 \mathrm{WO}_{x}$ sample is roughly the same as that for the $3 \mathrm{Pt}$. This suggests that there is no difference in Pt dispersion when Pt is evaporated on GDL or $\mathrm{WO}_{x}$. In addition, no decrease in electrochemical active surface area with time was seen for $3 \mathrm{Pt} 10 \mathrm{WO}_{x}$ (not shown here) as was
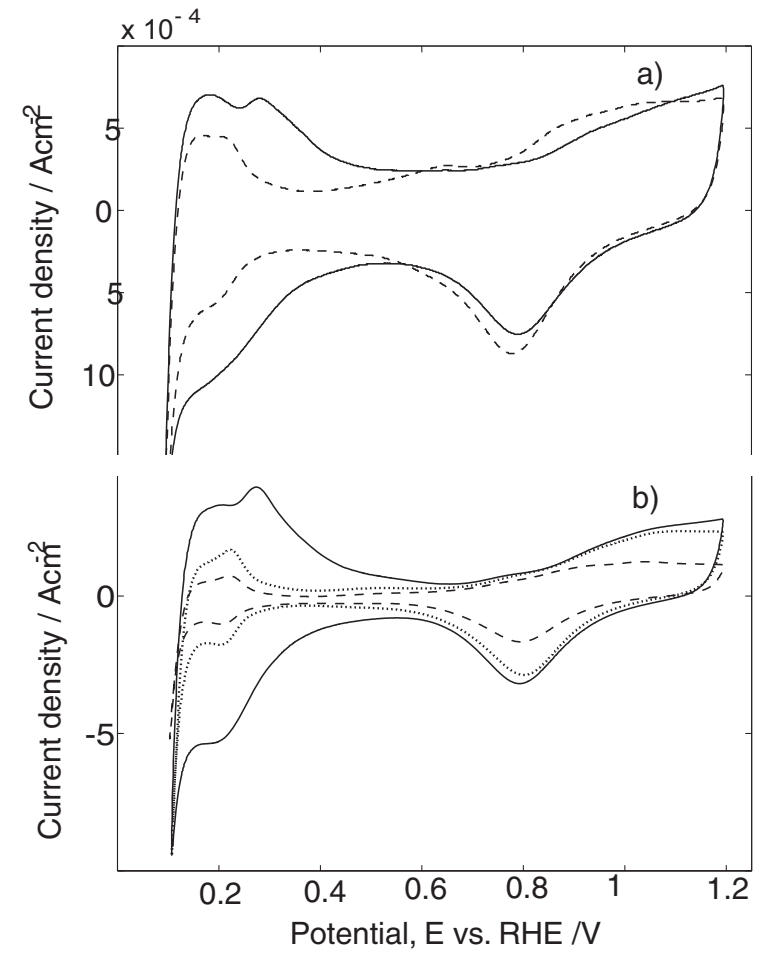

Fig. 7. Cyclic voltammograms of $3 \mathrm{Pt}$ (dashed) and $3 \mathrm{Pt} 10 \mathrm{WO}_{x}$ (solid) for electrodes with Nafion coating (a) as well as without Nafion (b). In (b), $3 \mathrm{Pt} 10 \mathrm{TiO}_{x}$ (dotted) is shown as reference. The voltammograms were recorded in a single cell fuel cell at $80^{\circ} \mathrm{C}$ and $90 \% \mathrm{RH}$ at a scan rate of $200 \mathrm{mV} \mathrm{s}^{-1}$.

seen for the Nafion covered sample in liquid electrolyte (Fig. 6a). If dissolution of $\mathrm{WO}_{x}$ was the cause for the decrease in liquid electrolyte, this is most likely much less pronounced in the fuel cell.

In Fig. 7b, the CV curves of the electrodes without Nafion are shown. The Pt oxide reduction peak is significantly higher on $3 \mathrm{Pt} 10 \mathrm{WO}_{x}$ compared to $3 \mathrm{Pt}$, similar to previous observations [46]. This is likely a sign of $3 \mathrm{Pt} 10 \mathrm{WO}_{x}$ having a larger ECSA, but due to the overlap between the hydrogen tungsten bronze formation and the Pt-H $\mathrm{H}_{\mathrm{UPD}}$, the latter could not be used to determine the surface area. Instead, we propose that $3 \mathrm{Pt} 10 \mathrm{TiO} \mathrm{O}_{x}$ can be used as Pt reference in the cyclic voltammograms, as discussed in Section 3.2. The $3 \mathrm{Pt} 10 \mathrm{TiO}_{x}$ and $3 \mathrm{Pt} 10 \mathrm{WO}_{x}$ samples showed a similar $\mathrm{Pt}$ oxide reduction response, indicating that the ECSA of these samples should be similar. This can be seen in Fig. 7b where it is also clear that $3 \mathrm{Pt} 10 \mathrm{TiO}_{x}$ displays only Pt characteristics in the $\mathrm{H}_{\mathrm{UPD}}$ area, i.e. no response from the $\mathrm{TiO}_{x}$ in the cyclic voltammogram. Thus, we propose that the $\mathrm{H}_{\mathrm{UPD}}$ on $\mathrm{Pt}$ for the $3 \mathrm{Pt} 10 \mathrm{WO}_{x}$ sample can be estimated to be similar to that of the $3 \mathrm{Pt} 10 \mathrm{TiO}_{x}$ sample as they show similar Pt oxide reduction charge. The remaining charge in the Pt-H $\mathrm{H}_{\text {UPD }}$ region for the $3 \mathrm{Pt} 10 \mathrm{WO}_{x}$ sample can be assigned to hydrogen bronze formation in the $\mathrm{WO}_{x}$.

\section{Conclusions}

Thin-film model electrodes deposited on GDL were used to examine several PEFC reactions in order to evaluate the influences of incorporating $\mathrm{WO}_{x}$ as a Pt support in the electrodes. Samples with $\mathrm{W}$ thicknesses between 0 and $40 \mathrm{~nm}$, with and without a top layer of $3 \mathrm{~nm}$ Pt were fabricated by thermal evaporation. XPS measurements indicated that $\mathrm{WO}_{3}$ was the most likely oxide species formed during spontaneous oxidation as the samples were subjected air. Pt was found to be in a metallic state and no shift in binding energies was detected for the different samples. SEM characterization revealed that the $\mathrm{WO}_{x}$ efficiently covered the exposed carbon 
particles in the microporous layer of the GDL. The $3 \mathrm{~nm}$ of Pt deposited on top formed separated Pt nanoparticles, similar to a commercial electrode.

The hydrogen tungsten bronze formation was clearly visible for all $\mathrm{WO}_{x}$ containing samples in fuel cell measurements. Pt changed the behavior of the hydrogen inclusion and exclusion of the tungsten bronzes. When Pt was present, the onset of hydrogen inclusion and exclusion were shifted to lower potentials and the rates of inclusion/exclusion were higher. However the amounts of formed bronzes were hardly affected by the Pt.

The increased Pt surface area on thicker $\mathrm{WO}_{x}$ films was found to be beneficial for the limiting current in the HOR. In addition, the oxidation of $\mathrm{CO}$ was shifted towards lower potentials, indicating that $\mathrm{Pt}$ on $\mathrm{WO}_{x}$ is more $\mathrm{CO}$ tolerant than Pt. However, with $\mathrm{WO}_{x}$ situated between the Pt and carbon support there will be an increase in the resistance of the electrode.

The model electrodes were also investigated in liquid electrolyte, where it was seen that the electrodes behaved very differently compared to the fuel cell case. In liquid electrolyte, Pt samples sprayed with Nafion showed a high ECSA whereas in the absence of Nafion, a very low ECSA was obtained. This is likely related to the hydrophobic properties of the GDL, hindering the liquid electrolyte to contact Pt when Nafion was not included. With a layer of $\mathrm{WO}_{x}$ between the GDL and Pt, however, a high ECSA was seen in the absence of Nafion. It is likely that $\mathrm{WO}_{x}$ can increase the wetting of the GDL and thus enable a higher Pt utilization. The Nafion coated samples of $\mathrm{Pt}$ on $\mathrm{WO}_{x}$ displayed a decreased initial ECSA and further cycling revealed a deactivation of the electrode. This can be an effect of dissolved $\mathrm{WO}_{x}$ degrading the Nafion or poisoning the Pt.

In fuel cell environment, the negative aspects of including Nafion on the Pt on $\mathrm{WO}_{x}$ samples was not seen, indicating that the deactivation process might be an effect of the liquid electrolyte. A similar ECSA was observed for both Pt and Pt on $\mathrm{WO}_{x}$ with Nafion. In the absence of Nafion, an increased ECSA was observed for Pt on $\mathrm{WO}_{x}$ layers of $10 \mathrm{~nm}$ and thicker. This increased Pt utilization can be related to $\mathrm{WO}_{x}$ ability to conduct protons and thus render a proton contact to a larger amount of Pt particles. It was found that $\mathrm{WO}_{x}$ can increase the Pt utilization for the HOR and increase the CO tolerance on the anode catalyst.

\section{Acknowledgments}

MISTRA (Swedish Foundation for Strategic Environmental Research) is gratefully acknowledged. The Competence Centre for Catalysis is hosted by Chalmers University of Technology and financially supported by the Swedish Energy Agency and the member companies AB Volvo, Volvo Car Corporation, Scania CV AB, GM Powertrain Sweden AB, Haldor Topsoe A/S, and the Swedish Space Corporation.

\section{References}

[1] S. Litster, G. McLean, J. Power Sources 130 (2004) 61.

[2] B. Hammer, J.K. Nørskov, Surf. Sci. 343 (1995) 211.
[3] W.C. Conner, J.L. Falconer, Chem. Rev. 95 (1995) 759

[4] Y.Y. Shao, J. Liu, Y. Wang, Y.H. Lin, J. Mater. Chem. 19 (2009) 46.

[5] E. Antolini, E.R. Gonzalez, Appl. Catal. B 96 (2010) 245.

[6] A.C.C. Tseung, K.Y. Chen, Catal. Today 38 (1997) 439.

[7] M.S. Whittingham, Solid State Ionics 168 (2004) 255.

[8] N. Yoshiike, S. Kondo, J. Electrochem. Soc. 130 (1983) 2283.

[9] M.A. Habib, S.P. Maheswari, J. Electrochem. Soc. 138 (1991) 2029.

[10] C.G. Granqvist, Sol. Energy Mater. Sol. Cells 60 (2000) 201.

[11] P.J. Kulesza, L.R. Faulkner, J. Electroanal. Chem. 248 (1988) 305.

[12] P.J. Kulesza, L.R. Faulkner, J. Am. Chem. Soc. 110 (1988) 4905.

[13] Y.M. Li, M. Hibino, M. Miyayania, T. Kudo, Solid State Ionics 134 (2000) 271.

[14] X.Z. Cui, H. Zhang, X.P. Dong, H.R. Chen, L.X. Zhang, L.M. Guo, J.L. Shi, J. Mater. Chem. 18 (2008) 3575.

[15] H. Kamal, A.A. Akl, K. Abdel-Hady, Phys. B 349 (2004) 192.

[16] P.J. Kulesza, L.R. Faulkner, J. Electrochem. Soc. 136 (1989) 707.

[17] P.J. Kulesza, B. Grzybowska, M.A. Malik, M.T. Galkowski, J. Electrochem. Soc. 144 (1997) 1911.

[18] K. Miecznikowski, P.J. Kulesza, J. Power Sources 196 (2011) 2595.

[19] X.Z. Cui, J.L. Shi, H.R. Chen, L.X. Zhang, L.M. Guo, J.H. Gao, J.B. Li, J. Phys. Chem. B $112(2008) 12024$.

[20] R. Ganesan, J.S. Lee, J. Power Sources 157 (2006) 217.

[21] S. Jayaraman, T.F. Jaramillo, S.H. Baeck, E.W. McFarland, J. Phys. Chem. B 109 (2005) 22958.

[22] M.K. Jeon, H. Daimon, K.R. Lee, A. Nakahara, S.I. Woo, Electrochem. Commun. 9 (2007) 2692.

[23] P.K. Shen, A.C.C. Tseung, J. Electrochem. Soc. 141 (1994) 3082.

[24] A.K. Shukla, M.K. Ravikumar, A.S. Arico, G. Candiano, V. Antonucci, N. Giordano, A. Hamnett, J. Appl. Electrochem. 25 (1995) 528

[25] L.X. Yang, C. Bock, B. MacDougall, J. Park, J. Appl. Electrochem. 34 (2004) 427.

[26] F. Micoud, F. Maillard, A. Bonnefont, N. Job, M. Chatenet, Phys. Chem. Chem. Phys. 12 (2010) 1182.

[27] F. Micoud, F. Maillard, A. Gourgaud, M. Chatenet, Electrochem. Commun. 11 (2009) 651

[28] N.P. Lebedeva, V. Rosca, G.J.M. Janssen, Electrochim. Acta 55 (2010) 7659.

[29] F. Maillard, E. Peyrelade, Y. Soldo-Olivier, M. Chatenet, E. Chainet, R. Faure, Electrochim. Acta 52 (2007) 1958

[30] L.G.S. Pereira, F.R. dos Santos, M.E. Pereira, V.A. Paganin, E.A. Ticianelli, Electrochim. Acta 51 (2006) 4061.

[31] B.S. Hobbs, A.C.C. Tseung, Nature 222 (1969) 556.

[32] B.S. Hobbs, A.C.C. Tseung, J. Electrochem. Soc. 120 (1973) 766.

[33] B.S. Hobbs, A.C.C. Tseung, J. Electrochem. Soc. 119 (1972) 580.

[34] J. Shim, C.R. Lee, H.K. Lee, J.S. Lee, E.J. Cairns, J. Power Sources 102 (2001) 172.

[35] A.J. Martín, A.M. Chaparro, L. Daza, J. Power Sources 196 (2011) 4187.

[36] R. Wlodarczyk, A. Kolary-Zurowska, R. Marassi, M. Chojak, P.J. Kulesza, Electrochim. Acta 52 (2007) 3958.

[37] K. Ota, A. Ishihara, S. Mitsushima, K. Lee, Y. Suzuki, N. Horibe, T. Nakagawa, N. Kamiya, J. New Mater. Electrochem. Syst. 8 (2005) 25.

[38] Y.J. Huang, H.H. Dai, W.S. Li, G.L. Li, D. Shu, H.Y. Chen, J. Power Sources 184 (2008) 348

[39] O. Savadogo, P. Beck, J. Electrochem. Soc. 143 (1996) 3842.

[40] X.Z. Cui, L.M. Guo, F.M. Cui, Q.J. He, J.L. Shi, J. Phys. Chem. C 113 (2009) 4134.

[41] Z. Zhang, X. Wang, Z. Cui, C. Liu, T. Lu, W. Xing, J. Power Sources 185 (2008) 941.

[42] P. Trogadas, V. Ramani, J. Electrochem. Soc. 155 (2008) B696.

[43] G. Orsini, V. Tricoli, J. Mater. Chem. 20 (2010) 6299.

[44] H. Chhina, S. Campbell, O. Kesler, J. Electrochem. Soc. 154 (2007) B533.

[45] K.Y. Chen, A.C.C. Tseung, J. Electrochem. Soc. 143 (1996) 2703.

[46] M. Wesselmark, B. Wickman, C. Lagergren, G. Lindbergh, Electrochim. Acta 55 (2010) 7590.

[47] J. Ihonen, F. Jaouen, G. Lindbergh, G. Sundholm, Electrochim. Acta 46 (2001) 2899.

[48] P. Brault, A. Caillard, A.L. Thomann, J. Mathias, C. Charles, R.W. Boswell, S. Escribano, J. Durand, T. Sauvage, J. Phys. D: Appl. Phys. 37 (2004) 3419.

[49] J.F. Moulder, W.F. Stickle, P.E. Sobol, K.D. Bomben, in: J. Chastain (Ed.), Handbook of X-ray Photoelectron Spectroscopy, PerkinElmer Corporation, Minneapolis, 1992.

[50] R.W. Lindström, K. Kortsdottir, M. Wesselmark, A. Oyarce, C. Lagergren, G. Lindbergh, J. Electrochem. Soc. 157 (2010) B1795

[51] M. Wesselmark, B. Wickman, C. Lagergren, G. Lindbergh, Electrochem. Commun. 12 (2010) 1585.

[52] H. Ekström, B. Wickman, M. Gustavsson, P. Hanarp, L. Eurenius, E. Olsson, G. Lindbergh, Electrochim. Acta 52 (2007) 4239. 